\title{
Vacation models in discrete time - Erratum
}

\section{Attahiru Sule Alfa}

Department of Electrical \& Computer Engineering

University of Manitoba, Winnipeg, Manitoba, Canada, R3T 5 V6.

(alfa@ee.umanitoba.ca)

The subscripts of the equation on page 12 of [1] should be adjusted and the equation should read as follows:

$$
R_{k}=A_{k, k+1}+R_{k} A_{k+1, k+1}+R_{k}\left[R_{k+1} A_{k+2, k+1}\right], \quad k \geq 0,
$$

and the range for the $G_{k}$ equation of page 13 should be $k \geq 1$.

\section{References}

- Alfa, A. S. (2003), "Vacation models in discrete time", QUESTA, 44,5-30, 2003.

(C) 2003 Kluwer Academic Publishers. Printed in the Netherlands. 